\title{
Coconut matting bezoar identified by a combined analytical approach
}

\author{
DA LEVISON,* PR CROCKER,* TA BOXALL, $†$ KJ RANDALL $\ddagger$
}

From the ${ }^{*}$ Department of Histopathology, St Bartholomew's Hospital, London, and the Departments of
$\dagger$ Surgery and $\ddagger$ Pathology, Orpington Hospital, Orpington, Kent

SUMmaRY A rare type of bezoar composed of coconut matting was found in the stomach of a caucasian man. The exact identity of the fibres was established by scanning electron microscopy, $\mathrm{x}$-ray energy spectroscopy, and microscopic infrared spectroscopy. This report illustrates the importance of these techniques for identifying the nature of foreign material.

Bezoars in the stomach consisting of a wide variety of materials, including hair, vegetable matter, and string are well documented curiosities. ${ }^{1-3}$ There have been few reports of bezoars composed of coconut matting $^{4}$; ; these reports date from the last century, and the patients were in mental institutions. In this report we describe our recent finding of a coconut matting bezoar in the stomach of an apparently mentally normal young man. We also present and illustrate the results of various analytical techniques used to identify precisely the component fibres.

\section{Case history}

A 28 year old caucasian man, apparently mentally normal, presented in October 1984 with a one month history of epigastric pain eased by taking food. He also complained of a full feeling in his oesophagus and of belching up wind from the stomach. When questioned he stated that he had noticed dark stools on two recent occasions. There were no positive physical signs, but barium meal showed a large mobile defect in the stomach, suggestive of a bezoar and a $1 \mathrm{~cm}$ filling defect on the posterior wall of the stomach. The presence of a bezoar was confirmed on endoscopy, and it was removed at laparotomy. An ulcerated lesion was also found in the distal part of the stomach and biopsied. The patient made an uneventful postoperative recovery. He was then further questioned before and after analysis of the bezoar about his "eating habits."

\section{PATHOLOGICAL EXAMINATION}

Sections of the biopsies of the ulcer showed nonspecific inflammatory changes thought to be in keeping with a traumatic ulcer. The bezoar was dark reddish brown in colour, shaped like an avocado pear, measured $10 \times 5 \times 5 \mathrm{~cm}$, and weighed $220 \mathrm{~g}$. It cut easily with a knife and seemed to consist of a mass of interwoven fibres, which, several observers suggested, resembled coconut matting (Fig. 1). Light microscopy showed the fibres to have partly smooth and partly rough surfaces with smaller strands attached. Scanning electron microscopic examination in a Jeol $35 \mathrm{CF}$ scanning electron microscope showed that the fibres measured $300 \mu \mathrm{m}$ in diameter, had smaller strands (40-50 $\mu \mathrm{m}$ diameter) attached and incorporated into their substance, and had variably smooth and rough surfaces and cores; the parts with a pithy appearance suggested a vegetable origin (Figs. 2a and 3a). Comparison by scanning electron microscopy of these fibres with human hair (scalp, axillary, and pubic), duffle coat (circa 1958, sleeve and toggle cord), cotton, nylon bristle, wool, string, sisal and fibres from both sides of a coconut mat, produced an almost exact match with the fibres taken from the coconut mat (Figs. 2b and 3b). X-ray energy dispersive spectroscopic analysis of the fibres, using a Kevex unispec system 7000 XES unit, showed only traces of sodium, suphur, aluminium, and calcium, indicating that the material was basically organic, in keeping with a vegetable or animal origin. Fibres from the bezoar and from a coconut mat were also examined by infrared spectroscopy in a Perkin-Elmer 1710 infrared Fourier transform spectrometer with infrared microscope (courtesy of Dr Stephen Allen, Perkin-Elmer Ltd). These fibres showed very closely matching spectra (Fig. 4), different to those of other vegetable fibres. Our conclusion that the bezoar was composed of fibres of coconut matting was supported by the metropolitan police forensic science laboratory where part of the specimen was examined. That laboratory came independently to the same conclusion on the 


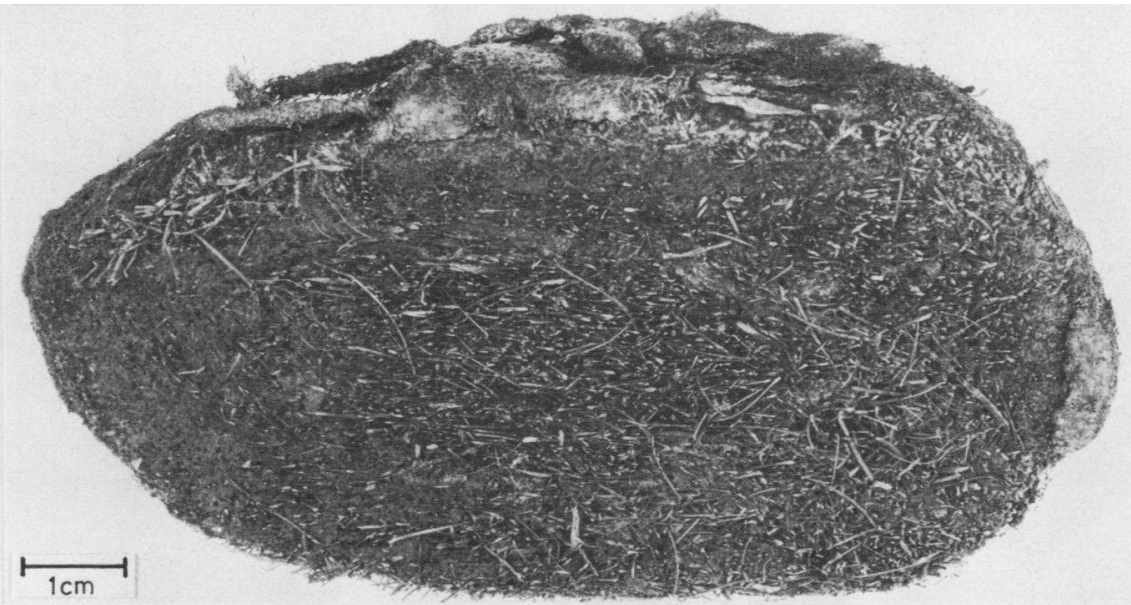

Fig. 1 Macroscopic view of cut surface and part of outer surface (at top) of bezoar. It is composed of interwoven fibres.
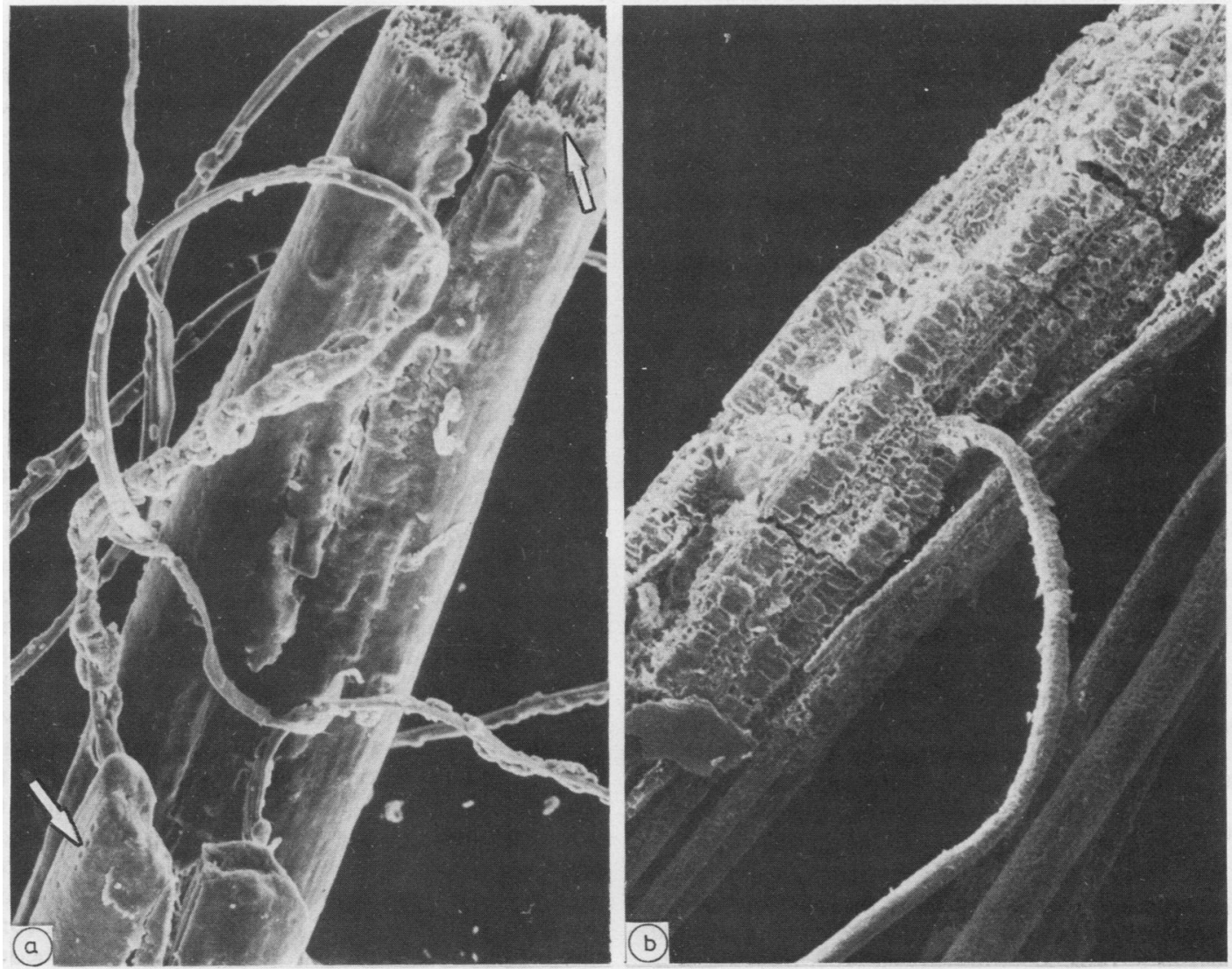

Fig. 2 Scanning electron microscopic appearances of fibre from bezoar (a) and a fibre from coconut mat (b). Both show attached and incorporated smaller strands and pithy surface markings, only partly preserved in (a) (arrows) $\times 60$. 


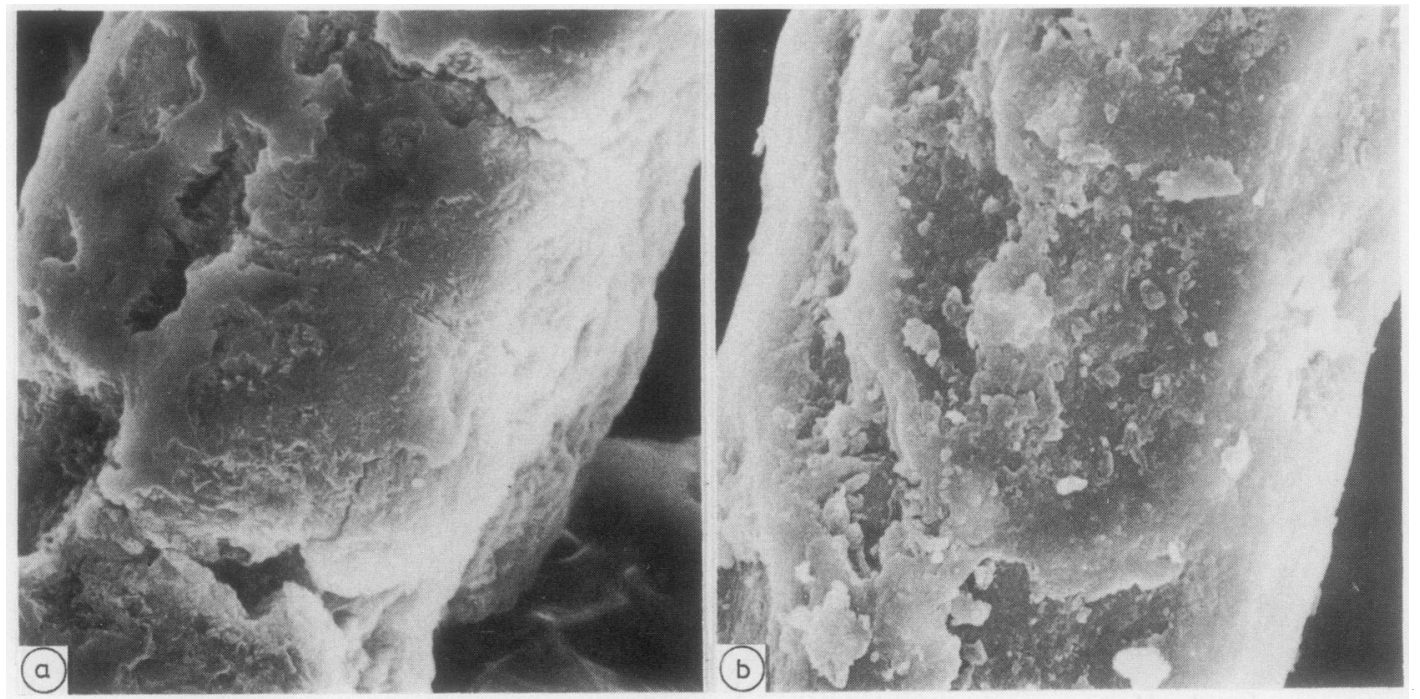

Fig. 3 Scanning electron microscopic appearances of (a) fibre from bezoar and (b) fibre from a coconut mat, showing virtually identical sizes and surface markings $\times 800$.

basis of light microscopic examination of the surface and transverse cuts of fibres and comparison with the illustrations in a new reference text. ${ }^{6}$

\section{Fi'rther history}

At his own request the patient viewed the operative specimen before analysis. At that stage he did admit having chewed his duffle coat as a child hence our

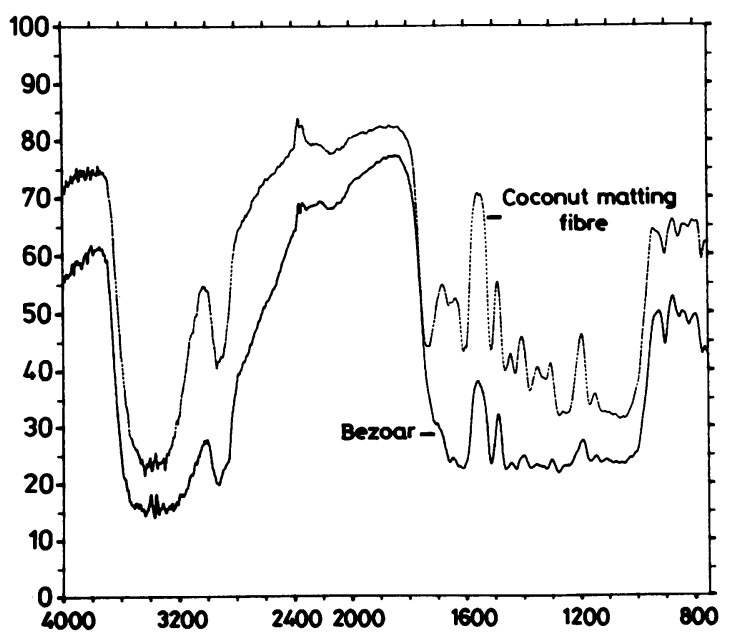

Fig. 4 Infrared spectra of coconut mat fibre and fibre from the bezoar. Note matching absorption bands at 2900 . $1600,1520,1440,1380,1320,1280,1160,900,850,820$, and $770 \mathrm{~cm}^{-1}$. Few extra bands in bezoar probably represent material incorporated in stomach. inclusion of fibres from an "age matched" duffle coat for scanning electron microscopic comparison. Once the full analytical results were known the patient was presented with our findings. He then admitted chewing various materials as a teenager, in particular, coconut matting.

\section{Discussion}

A bezoar is a mass of foreign material in the stomach or intestine. ${ }^{3}$ In children, adolescents, and in mentally defective adults these usually consist of balls or mats of hair and are known as trichobezoars. In children these are much more common in females than in males, probably due simply to the length of hair available for chewing and not to any inborn psychological trait. Trichobezoars produce abdominal pain, nausea, and weight loss, but seldom obstruction. In normal adults phytobezoars, consisting of vegetable or plant material, predominate; in America the persimmon (date plum) is the most common cause. These phytobezoars are cylindrical, oval, or spheroidal, with a smooth bossed or pitted surface and are dark brown, green, or black in colour. They are usually friable and shrink on dessication. Phytobezoars may obstruct the intestine or remain in the stomach. Combined trichophytobezoars are recognised, and other concretions including boluses of food also form bezoars, but we are only aware of one probable ${ }^{4}$ and one definite 5 previous report of bezoars caused by coconut matting. The "probable" report refers to coconut fibre rather than coconut matting, but it seems to mean fibre from a coconut mat. Bezoars composed of 
the edible part of a coconut are usually described as composed of coconut fibres, and sometimes result from eating large quantities of coconut pie $^{7}$; these are apparently more common than coconut matting bezoars.

Another interesting aspect, apart from the rarity of our case, is the claimed long period of time (10 years) after the ingestion of the matting had stopped and the onset of symptoms. This information may not, of course, be accurate. Higgins' patient, ${ }^{5}$ however, had epigastric pressure discomfort for 10 years attributed in retrospect to three coconut matting bezoars found in his stomach at necropsy. Thus such bezoars may be relatively asymptomatic for long periods. Our patient may well have continued to be asymptomatic had he not developed a pressure ulcer and consequently, epigastric pain.

This case also shows the value of modern analytical techniques in diagnostic pathology. Our patient did not admit his liking for coconut matting until he was presented with the scientific proof of the nature of the fibres. It certainly helps to apply common sense as well as modern technology to the investigation of such material: macroscopic and light microscopic examination of the specimen did point us in the correct direction. Though x-ray energy spectroscopy was useful here, mainly in a negative sense, and scanning electron microscopy and infrared spectroscopy gave us the positive identification, x-ray energy spectroscopy has proved its specific diagnostic value in the past, particularly when we were pursuing the identity of very small amounts of foreign material in paraffin sections. $^{8-10}$ X-ray energy spectroscopy will, however, only identify inorganic elements of atomic number greater than 11 (sodium). Conventional infrared spectroscopy, on the other hand, will identify compounds including those composed only of low atomic number elements. Standard preparations for conventional infrared spectroscopy, however, are normally made as mulls or ground with alkaline halides, such as potassium bromide $(\mathrm{KBr})$, and require a minimum sample of $1.5 \mathrm{mg}$. Material like these coconut mat fibres or microscopic particles in sections have not been suitable for conventional infrared spec- troscopic analysis. The new spectrometer with infrared microscope, which was used here, can obviously cope with small fibres and holds promise for microscopic particles in sections.

Finally, and in passing, we wonder if coconut matting represents the ultimate in high fibre diets!

We thank Miss Caroline Judge, Mr J Hopwood, and Mrs Dawn O'Keefe for secretarial and photographic work. We also thank the North East Thames Regional Health Authority; the Wellcome Trust; and the St Bartholomew's Hospital Joint Research Board, who, together, financed the purchase of our scanning electron microscopic and $\mathrm{x}$-ray energy spectroscopic analytical apparatus.

\section{References}

${ }^{1}$ Debakey M, Ochsner A. Bezoars and concretions. Surgery 1938;4:934-63.

${ }^{2}$ Debakey M, Ochsner A. Bèzoars and concretions. Surgery 1939:5:132-60.

${ }^{3}$ Morson BC, Dawson IMP. Gastrointestinal pathology. Oxford: Blackwell Scientific Publications, 1979:202.

${ }^{4}$ Quain, Bucknill JC. The stomach of an insane patient filled with cocoa-nut fibre, which caused death by perforation of this viscus. Transactions of the Pathological Society (London) 1853-1854;5:145-6.

${ }^{5}$ Higgins WH. Three hard massess of cocoa-nut fibre found after death in the stomach of a lunatic. Lancet 1878;ii:290.

${ }^{6}$ Catling D, Grayson J. Identification of vegetable fibres. London: Chapman Hall, 1982.

${ }^{7}$ Gordon WB, Newton BL, Tuttle UD. Intestinal obstruction secondary to coconut fibres. Am J Surg 1958;24:759-62.

${ }^{8}$ Crocker PR, Toulson E, Levison DA. Particles in paraffin sections demonstrated in the backscattered electron image (BEI). Micron 1982;13:437-46.

${ }^{9}$ Levison DA, Crocker PR, Smith AP, Blackshaw AJ, Bartram CI. The varied light and scanning electron microscopic appearances of barium sulphate in smears and histological sections. $J$ Clin Pathol 1984;37:481-7.

${ }^{10}$ Levison DA, Crocker PR, Lee G, Shepherd NA, Smith AP. Unexpected inorganic elements in oral lesions: results of X-ray energy spectroscopy (XES) on particulate matter in paraffin sections. Journal of Pathology and Bacteriology 1984;144:119-29.

Requests for reprints to: Dr David A Levison, Department of Histopathology, St Bartholomew's Hospital, West Smithfield, London EC1A 7BE, England. 